\title{
Los capítulos que se le olvidaron a ELEMENTAL: lógicas informales para el diseño de vivienda social
} The chapters that ELEMENTAL forgot: informal logics for the design of social housing

Autores:

María Belén Granja Bastidas* maria.belen.granja.bastidas@gmail.com

Marlown Cuenca* marlowncg@gmail.com

*Universidad Politécnica de Madrid

España

Recibido: 29/Mar/2019 Aceptado: 04/Jul/2020

\section{Resumen}

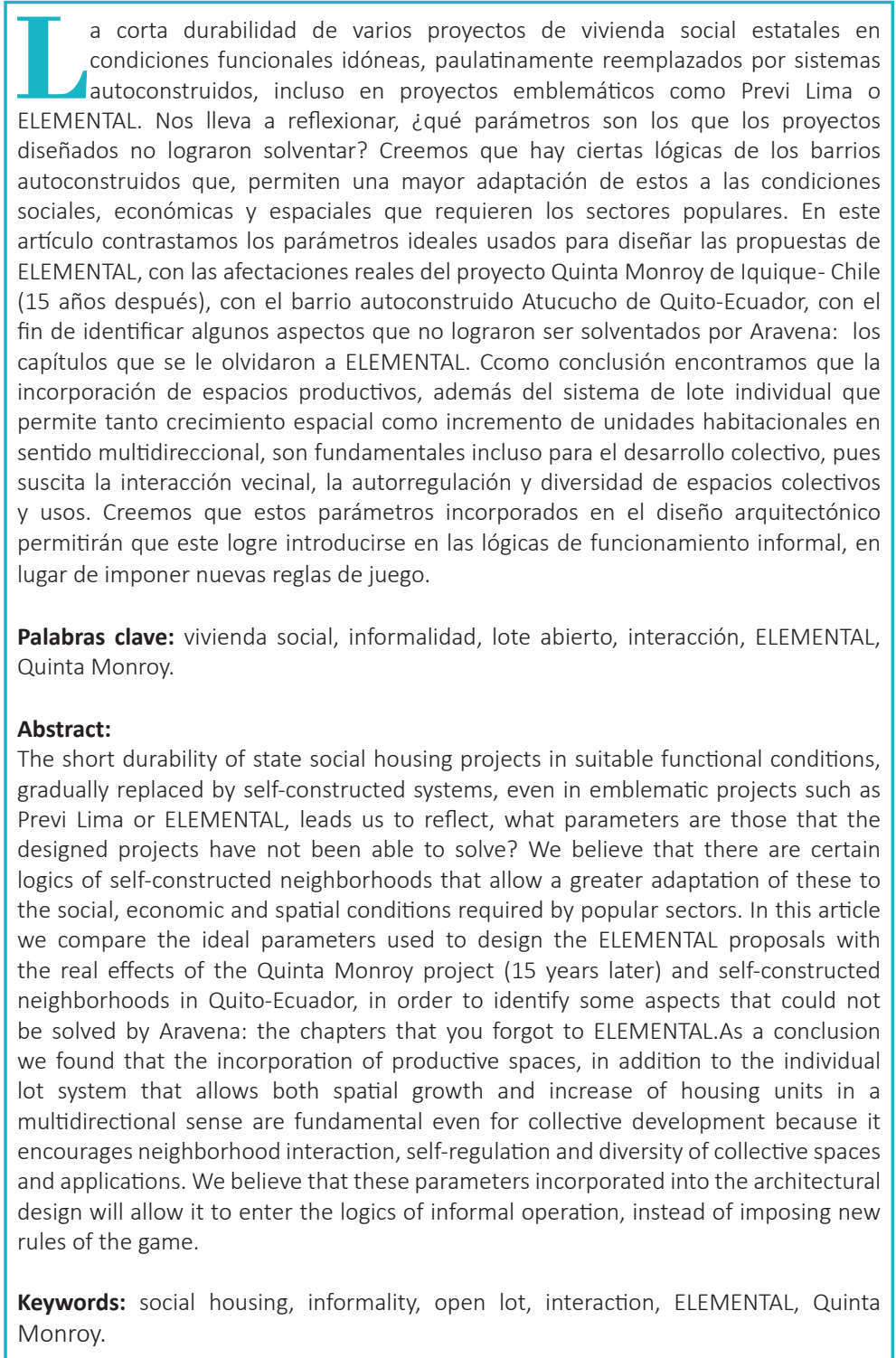




\section{Introducción}

El crecimiento urbano del siglo XX no ha satisfecho la necesidad de vivienda en todos los ámbitos socioeconómicos, y en consecuencia el déficit de vivienda de calidad para el alojamiento masivo es el mayor problema de la ciudad contemporánea. Aunque las soluciones apoyadas en la industria cuantitativamente parecían la respuesta, la crisis inmobiliaria del 2007 y los resultados negativos de los proyectos de vivienda social en México, con más de cinco millones de viviendas en estado ruinoso por abandono en menos de 10 años de su construcción (Blas, 2015), evidencian, especialmente en Latinoamérica, que los barrios informales autoconstruidos, aun con su limitada factura, subsisten imponiéndose incluso sobre sistemas planificados de mayor calidad, como Previ Lima (Davis, 2014; Huidrobo, Torres y Tugas, 2010).

En este marco destaca ELEMENTAL ${ }^{1}$, que retoma la búsqueda de fusionar ambos modelos, aprovechando los recursos que mueve la autoconstrucción $y$, en conjunción con la intervención estatal, generar una propuesta viable; pero luego de 15 años de la intervención podemos notar que, aunque factores como el crecimiento de la vivienda eran condicionantes de partida del proyecto, las modificaciones y ampliaciones, de acuerdo con los parámetros pensados, ocurrieron solo en la primera intervención. Es decir, son vigentes solo en periodos cortos de entre 5 y 10 años. Además, paulatinamente aparecen intervenciones que exceden la altura establecida como límite y ocupan los retiros frontales o patios, afectando la estabilidad de la estructura y la calidad urbana y arquitectónica del conjunto, replicando nuevamente condiciones, problemas y características similares a las de barrios informales no dirigidos (Barros, 2015; Millones, 2017).

Creemos que este fenómeno de informalización ${ }^{2}$ existe porque-por irracionales que aparentenlos mecanismos informales son sistemas emergentes que responden, en mejor medida, a las necesidades espaciales y de hábitat, y se adaptan a los problemas sociales, económicos y geográficos de los sectores populares. Los sistemas planificados no han logrado incorporar estas características flexibles mediante las cuales los asentamientos ilegales podrían convertirse en vehículos de cambio social (Turner, 2018). Por ello, con todas sus carencias, sobreviven e incluso se imponen sobre sistemas planificados de aparente mayor calidad espacial.
Como plantea Davis (2014), estos argumentos han sido utilizados para apoyar una teoría económica que desvincula completamente al Estado como gestor principal y que termina siendo ideal y conveniente para las políticas Neoliberales (Massad, 2016). Basándonos en el hecho de que la gente espontáneamente opta por estos sistemas de vivienda por ser flexibles (García, Torres y Tugas, 2008), es importante el estudio de estos para encontrar soluciones viables y sostenibles en el tiempo.

El artículo se fundamenta en un análisis comparativo de los parámetros ideales de diseño planteados por ELEMENTAL (Aravena, Lacobelli y Elemental, 2012), para el desarrollo de Quinta Monroy, con sistemas de crecimiento reales de desarrollo informal en el barrio Atucucho de la Ciudad de Quito-Ecuador. Pretendemos identificar qué aspectos de diseño no lograron ser solventados en la propuesta de Aravena, los que serían "los capítulos que se le olvidaron a ELEMENTAL", y que pueden dar ideas alternativas para que el diseño arquitectónico logre introducirse en las lógicas de funcionamiento informal, en lugar de imponer nuevas reglas de juego.

\section{Metodología}

Contrastaremos los cinco parámetros ideales planteados por Aravena et al. (2012) para el diseño del concurso mundial de vivienda social lanzado por ELEMENTAL en el 2003, con los efectos y procesos reales en el tiempo de lo que pasa en el proyecto de Quinta Monroy y el barrio informal Atucucho de Quito.

La evidencia de los procesos y modificaciones del proyecto ELEMENTAL se fundamentarán en un análisis documental que reúne la síntesis descrita en Aravena et al. (2012), más artículos de análisis y critica del proyecto Quinta Monroy recogidos en Adler y Vera (2018), Barros (2015), Millones (2017), entre otros.

Los procesos y cambios en el tiempo del barrio informal Atucucho son parte de la tesis doctoral del autor, enfocada en identificar el proceso de construcción de los barrios informales en pendiente en la Ciudad de Quito. La toma de datos de este estudio se realizó mediante lo que denominamos Censo Háptico, que consiste en recorrer un muestrario de 100 viviendas del barrio Atucucho, acompañados de sus propios usuarios. A través de estos recorridos es posible reconstruir la secuencia de crecimiento de la vivienda, así como la valoración espacial actual de la misma.

\section{Contextualización}

\subsection{Justificación casos de estudio: Quinta Monroy y Atucucho}

En principio, hemos tomado dos casos en donde los asentamientos son informales: el primer caso, Quinta Monroy, es un asentamiento informal de treinta años, con estructuras sociales arraigadas, que es una de las estrategias principales para el proyecto de ELEMENTAL ${ }^{1}$ ELEMENTAL es el equipo de Arquitectos, encabezados por Alejandro
Aravena, que desarrolla el primer proyecto en Quinta Monroy, con un sistema hibrido entre el edificio en barra y la vivienda autoconstruida (Aravena, Lacobelli y Elemental, 2012).

2 Muchos autores utilizan el término "slumización", como Borja (2011, p. 132) 
(Figura 1, foto 1); el segundo caso, Atucucho, es un barrio informal de treinta y cinco años de asentamiento, con una fuerte organización barrial (Figura 2). Estos dos barrios tienen características similares, con la diferencia que, en Quinta Monroy, se hizo tabla rasa y se implantó una solución arquitectónica ideal (Figura 1, foto 2), solución que luego de diez años volvió a informalizarce (Figura 1, foto 3).
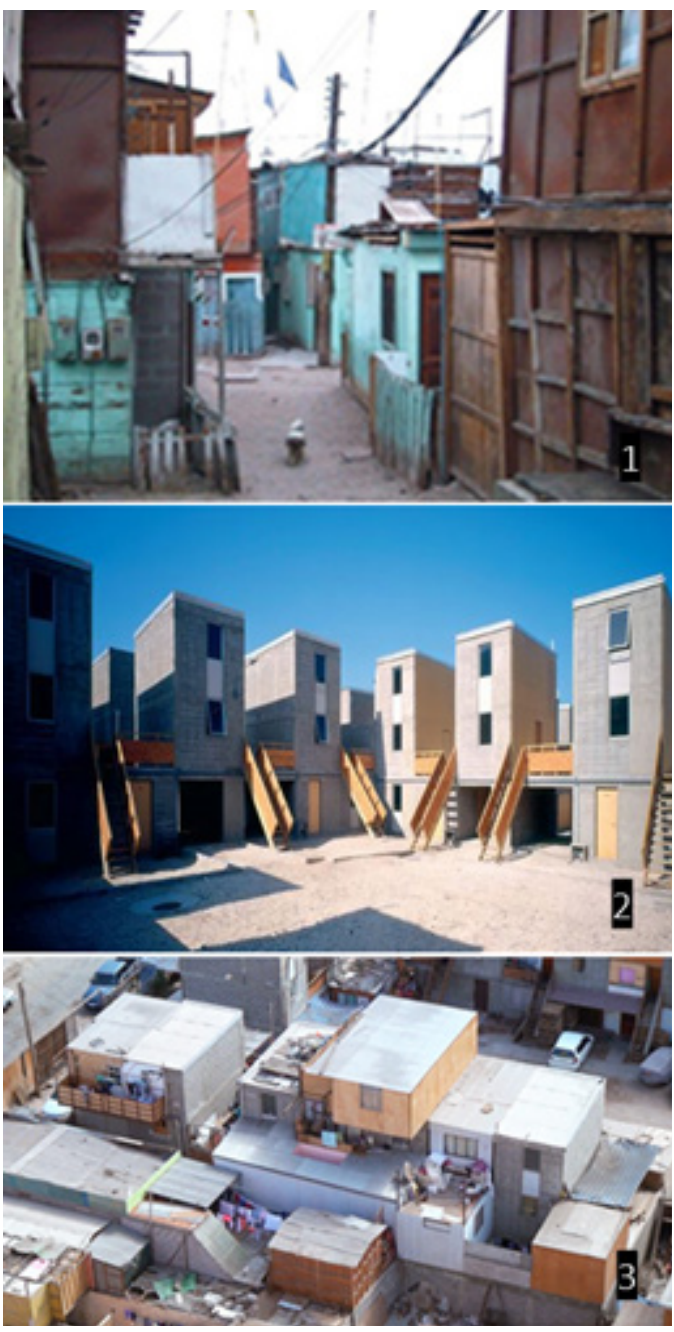

Figura 1: Fotografía 1: barrio informal Quinta Monroy, año 2002; fotografía 2: Proyecto de Elemental Quinta Monroy, año 2004; fotografía 3: informalización de la propuesta de Elemental Quinta Monroy, Iquique - Chile, año 2017

Fuente: Fotografías 1 y 2 tomadas de Aravena ELEMENTAL (2012); fotografía 3 tomada de Millones (2017)

Uno de los casos de informalización más analizados es Previ Lima (Perú), (Huidrobo et al., 2010); en QuitoEcuador tenemos casos de informalización como el Plan Solanda y algunos proyectos del MIDUVI. Según Cuenca (2019) los programas mono-funcionales de vivienda social no permiten el desarrollo de las personas, por lo tanto la informalización es un proceso de adaptación a las estructuras económico sociales de la ciudad.
Los dos casos de estudio son clave para evitar la destrucción de otros procesos socio-espaciales, porque al contrastarlos, podemos encontrar criterios para entender el complejo y diverso escenario de la ciudad informal. Además, tenemos una amplia investigación con un muestrario representativo de 100 viviendas levantadas y analizadas en el barrio de Atucucho.

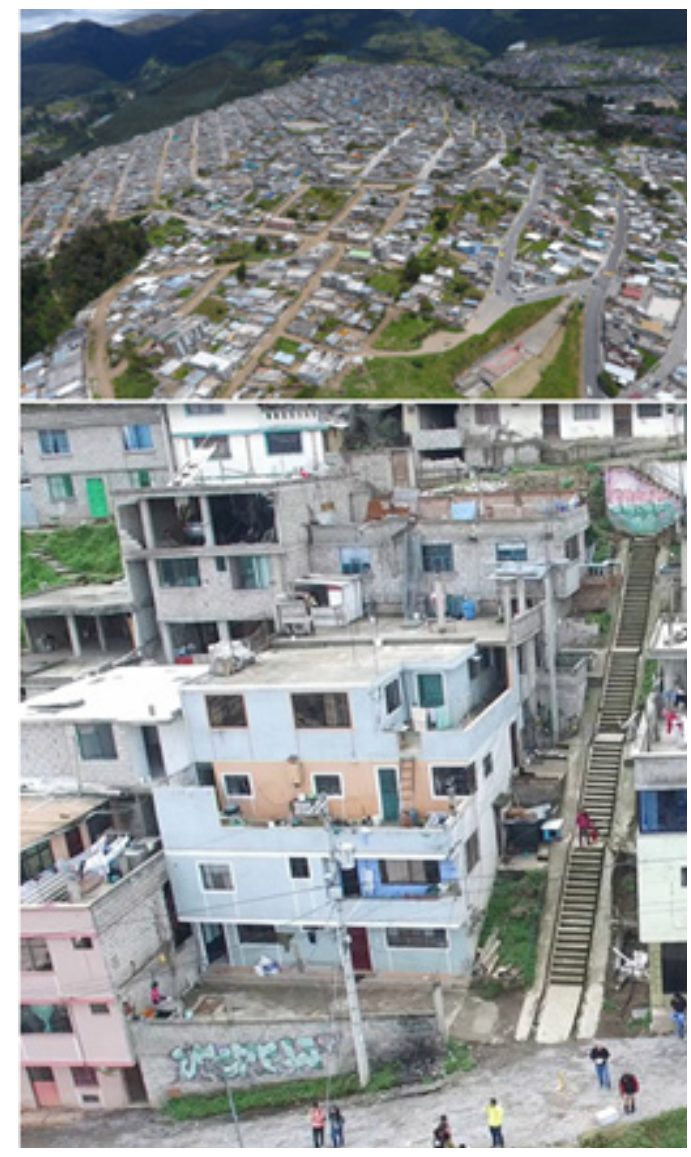

Figura 2: Fotografía superior: barrio informal Atucucho, noroccidente de Quito; fotografía inferior: viviendas informales al interior del barrio Atucucho, Quito Ecuador

Fuente: Autor (2017)

\subsection{El diseño de vivienda social en Quinta Monroy}

La vivienda social es sin duda el mayor conflicto en el problema del desarrollo urbano mundial y principalmente del denominado Sur global (Adler y Vera, 2018; Cueva, Ospina y Navas, 2011), donde las políticas gubernamentales son insuficientes tanto en la inversión como en la aplicación de leyes; por lo tanto, la solución dominante es la autoconstrucción (Adler y Vera, 2018; Schütz, 1996). Las intervenciones gubernamentales en vivienda social con bajo presupuesto parten de la premisa de "achicar y alejar" (Aravena y Lacobelli, 2012) y en estas condiciones la vivienda en poco tiempo se desvaloriza, se deteriora, lo que termina a la larga incrementando la problemática social. 
El proyecto piloto Quinta Monroy, ejecutado el año 2003, retoma la idea de aprovechar la autoconstrucción como complemento a los escasos fondos estatales para conseguir lo que sus autores definen como una vivienda de calidad idónea para clase media.

La innovación del planteamiento, según Aravena y Lacobelli (2012), es que "la incrementabilidad debe ser diseñada... lo que significa anticipar en la forma inicia esa segunda mitad que permitirá alcanzar el estándar de clase media... para que la vivienda deje de ser un gasto social y se convierta en una inversión". Para esto, Aravena modifica la concepción general con la que implementan los programas estatales de Chile y varios países latinoamericanos ${ }^{3}$, y establece cinco parámetros cualitativos, que son:

- Buena localización.

Densidad suficiente que permita pagar suelo caro.

- Crecimiento armónico en el tiempo.

Conquista de la arista/ prever espacio para ampliaciones.

- Familia extensiva.

Espacios colectivos de alrededor de 20 familias.

- Construir estratégicamente la primera mitad.

Dejar hecha la estructura para el estado final/muros medianeros estructurales y contrafuego+ baño+ cocina+ escalera+ cubierta final.

- $\quad$ ADN de clase media.

$72 \mathrm{~m} 2$ o 4 dormitorios de $3 \times 3$ con espacio para Closet o cama matrimonial/baños que puedan tener Tina y lavadora/Lejos de la casa y posibilidad de tener parqueadero (Aravenay Lacobelli, 2012, p.500).

\subsection{Análisis de caso: procesos informales en Atucucho, Quito - Ecuador}

La ciudad de Quito - Ecuador se encuentra en los Andes, a una media de 2.850 m.s.n.m., lo que condiciona una morfología lineal en sentido norte-sur. Por ello muchos de los asentamientos informales se ubican en laderas.

El crecimiento informal empieza a partir de 1970, con el boom petrolero (Carrión y Erazo, 2012). La demanda de vivienda social se resuelve entre un 65-80 \% mediante la autoconstrucción.

El desarrollo de este artículo se centrará en el barrio Atucucho, de ocupación ilegal, ubicado en la zona noroccidental de la ciudad, al igual que otros barrios informales como La Roldós, La Pisulí y La Comuna. Una particularidad es que antes de la invasión esta zona fue pensada para el desarrollo de barrios de clase media y alta (Zevallos, 1996).

\section{Reconstrucción narrativa del proceso de conformación del barrio Atucucho}

Según el relato reconstruido por el autor, a través de testimonios y entrevistas in situ, el proceso de conformación del barrio sería el siguiente: La noche

\footnotetext{
${ }^{3}$ Se refiere a los sistemas de implementación de vivienda social a través de un bono económico estatal. En el caso de Ecuador, a través de entidades como el MIDUVI (Ministerio de Desarrollo Urbano y Vivienda).
}

del 28 de marzo del año 1988, seiscientas familias se congregan en la denominada " $Y$ de Atucucho". Suben el empinado terreno y empiezan a trazar las primeras calles, ganándole tiempo al amanecer. En una acción colectiva y sincronizada, se empieza a marcar los lotes de $8 \times 13 \mathrm{~m}$, que se adecuan a la sinuosa forma del terreno. Así comienza la historia de Atucucho, una acción colectiva que define su forma en la interacción con el entorno y la premura del tiempo.

La instalación del barrio en un área de protección ecológica planificada con otro fin provoca que, para permanecer en el sector, fuera necesario vivir allí en una vivienda precaria hecha con materiales provenientes de árboles de la zona (Peltre-Wurtz, 2004).

En el año 1996 el barrio es reconocido como un asentamiento de hecho y empiezan a edificar mediaguas ${ }^{4}$ que paulatinamente son reemplazadas por casas, con sistemas estructurales definitivos como hormigón armado. Paralelamente, en el barrio se van asfaltando calles e incrementando servicios como: alcantarillado, luz eléctrica y agua potable para cada vivienda.

Para el año 2010, contando con 17.000 habitantes, el barrio es legalizado. Luego de 30 años de autoconstrucción, muchas viviendas albergan incluso a los hijos de los hijos. Es decir, que en la actualidad es la historia de tres generaciones. Todavía existen viviendas en precarias condiciones, pero más del $65 \%$ han definido ya su sistema estructural y funcional.

\section{Reconstrucción espacial del proceso de construcción del barrio Atucucho}

En el año 1984, cuando el lugar era una hacienda, existían rastros de un eje primigenio que para el año 1991 (Figura 3 ) es retomado como eje vertebral, conformando la calle Julio y Carlota Jaramillo, por donde hoy circulan los buses.

Por esta razón, planteamos que contrario a lo que afirman Sáez, García y Roch (2010) y Habraken (1998), no es el crecimiento de la casa en colectivo el que consolida la vía, sino que sería el trazado de la calle un acuerdo tácito de partida que Salingaros, Brain, Duany, Mechaffy y Philibert-Petit (2006) denominan como "el código generativo del barrio", y como esta se traza paralela a la topografía, el barrio luce como un manto que se asienta en el lugar, recubriendo la montaña.

El crecimiento de la casa, en cambio (Figura 4), inicia desde el lote individual, pero en relación directa al trazado vial en la manzana. Este proceso se configura como una serie de pixeles ${ }^{5}$ que crecen direccionados en interacción con los lotes contiguos, formando entre sí nuevas unidades colectivas de vivienda, articuladas en torno a la calle de acceso, con la que conforman pequeñas vecindades (Monteys, 2017) que se conectan a la red global del barrio.

\footnotetext{
${ }^{4}$ Mediagua: término generalizado para definir una vivienda transitoria, con las condiciones mínimas de techado y cerramiento para habitarla.
} 


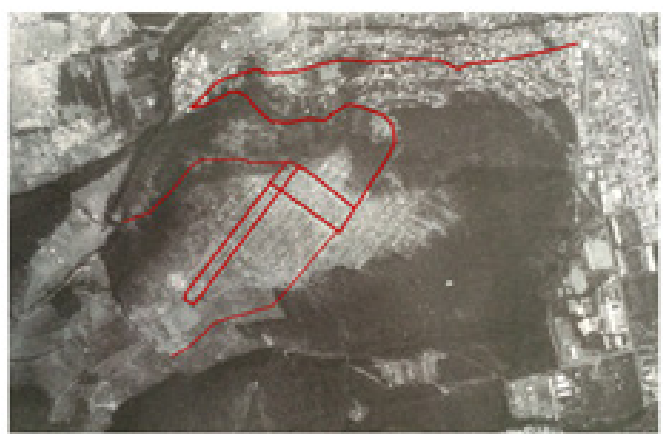

1991

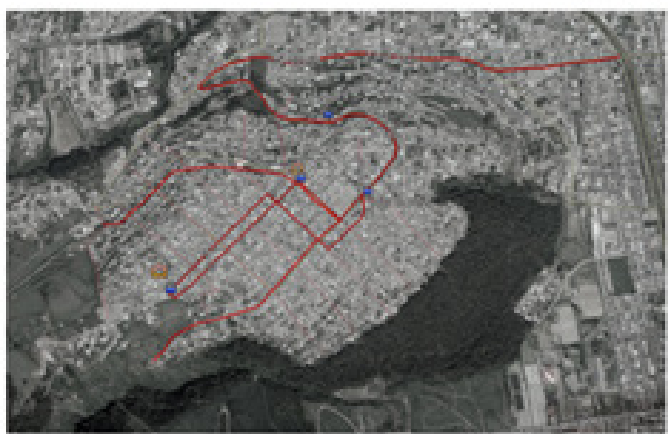

2018

Figura 3: Procesos de crecimiento del barrio de Atucucho a través del eje vial como estructurador espacial Fuente: Del Autor en base a fotografía aérea de IGM (Instituto Geográfico Militar). (1991 - 2018)
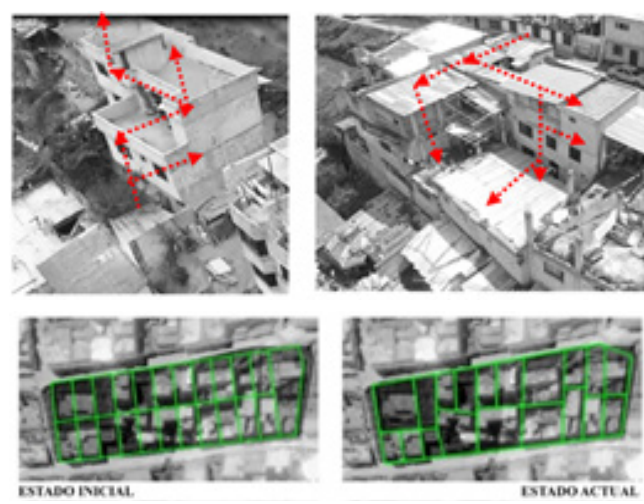

Figura 4: Proceso de Crecimiento de la Casa en el barrio Atucucho, Quito- Ecuador

Fuente: Del autor a partir del repositorio personal (2017)

Entonces, la "forma colectiva" ${ }^{6}$ es un sistema complejo integral de subelementos interconectados entrelazados entre sí. Los pixeles espaciales que conforman la casa (Figura 4) se adicionan desde un principio de agregación modular, y la manera en que se concatenan estos módulos define la forma del elemento final. Esta noción espacial es posible con el sistema de hormigón armado desde un pórtico base de cuatro columnas al que se agregan los demás pixeles mediante la

\footnotetext{
${ }^{5}$ Pixeles: unidad básica que conforma una entidad colectiva mayor.

${ }^{6}$ Término utilizado por Maki (1964) para referirse a la configuración urbana de formas agrupadas de la ciudad tradicional.
}

prolongación de las varillas de las vigas y columnas de los extremos hacia cualquier dirección posible.

\section{Análisis comparativo de ELEMENTAL y Atucucho}

\section{1. Buena localización}

\section{Condiciones ideales de localización propuestas por ELEMENTAL}

Como plantean Aravena y Lacobelli (2012), la ubicación y cercanía del proyecto a zonas centrales es fundamental, pues facilita el desenvolvimiento cotidiano y además el costo por superficie en zonas estratégicamente ubicadas, lo que garantizaría la revalorización de la vivienda. El problema entonces es conseguir una densidad media idónea que también permita que el valor de los suelos centrales y accesibles sean rentables para los promotores inmobiliarios. En este sentido "una densidad de 150 familias por hectárea permitiría compensar el alto costo del suelo" (Aravena et al., 2012).

\section{Condiciones reales aplicadas en Quinta Monroy}

Quinta Monroy se ubica a menos de $4 \mathrm{~km}$ de la zona Central de lquique, en Chile, con conexión directa a la Av. Soldado Pedro Pablo, uno de los ejes principales de circulación y conectividad directa al transporte público. La densidad media con la que se construyó es 450-600 hab/Ha, para lo que se cambió el uso original del asentamiento informal de Quinta Monroy de una familia por lote por el "edificio paralelo" (Aravena et al., 2012), en el que una familia se aloja en planta baja y la otra en un dúplex en planta alta. Esta densidad permitió inicialmente compensar el alto costo del terreno en la localidad. Sin embargo, partir de la densidad máxima que una estructura espacial puede soportar le brinda poca capacidad de crecimiento a futuro, como podemos observar en la Figura 5.

Además, como afirma Millones (2017), las inmediaciones del barrio y el desarrollo de Iquique han generado una alta demanda de crecimiento en altura, lo que vuelve poco atractiva y competitiva la vivienda de ELEMENTAL para la venta.

\section{Condiciones de localización: barrio informal Atucucho, Quito - Ecuador}

En la planificación de la ciudad de Quito los barrios populares se ubican mayoritariamente hacia el sur, según el Plan Jones Odriozola (Plan Regulador de Quito, 19421945), pero en los años 80 la creación de la Avenida Occidental como anillo periférico que bordea todo el límite oeste provocó varias invasiones en la zona noroccidental (los barrios populares como La Pulida, La Roldós, La Pisulí y Atucucho), destinada originalmente a viviendas de alto standing. Estas zonas se vuelven de particular interés para los invasores, precisamente por 


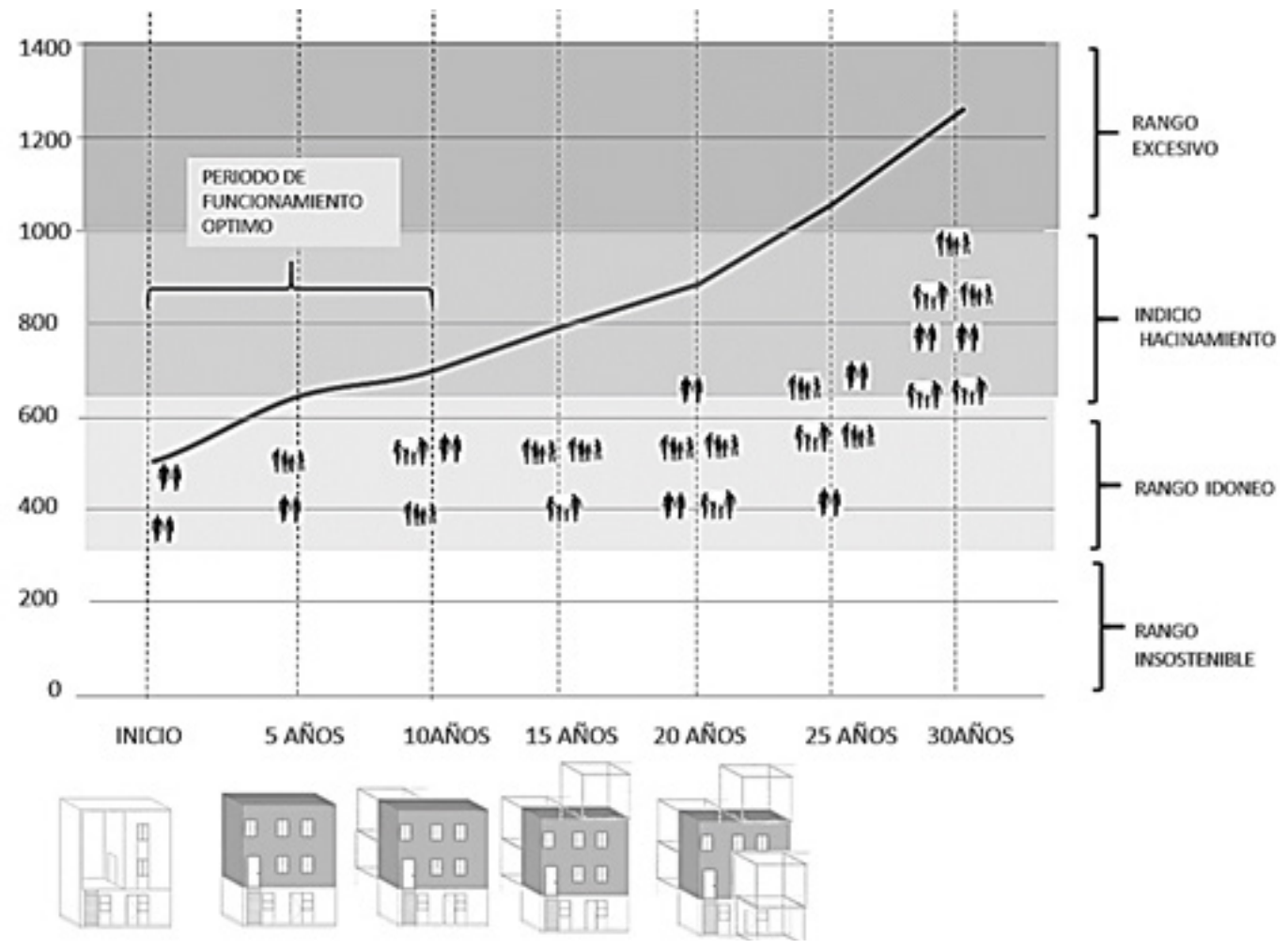

Figura 5: Densidad y crecimiento en el tiempo en las viviendas de Quinta Monroy Fuente: Del Autor a partir de datos analizados en Quinta Monroy (2017)

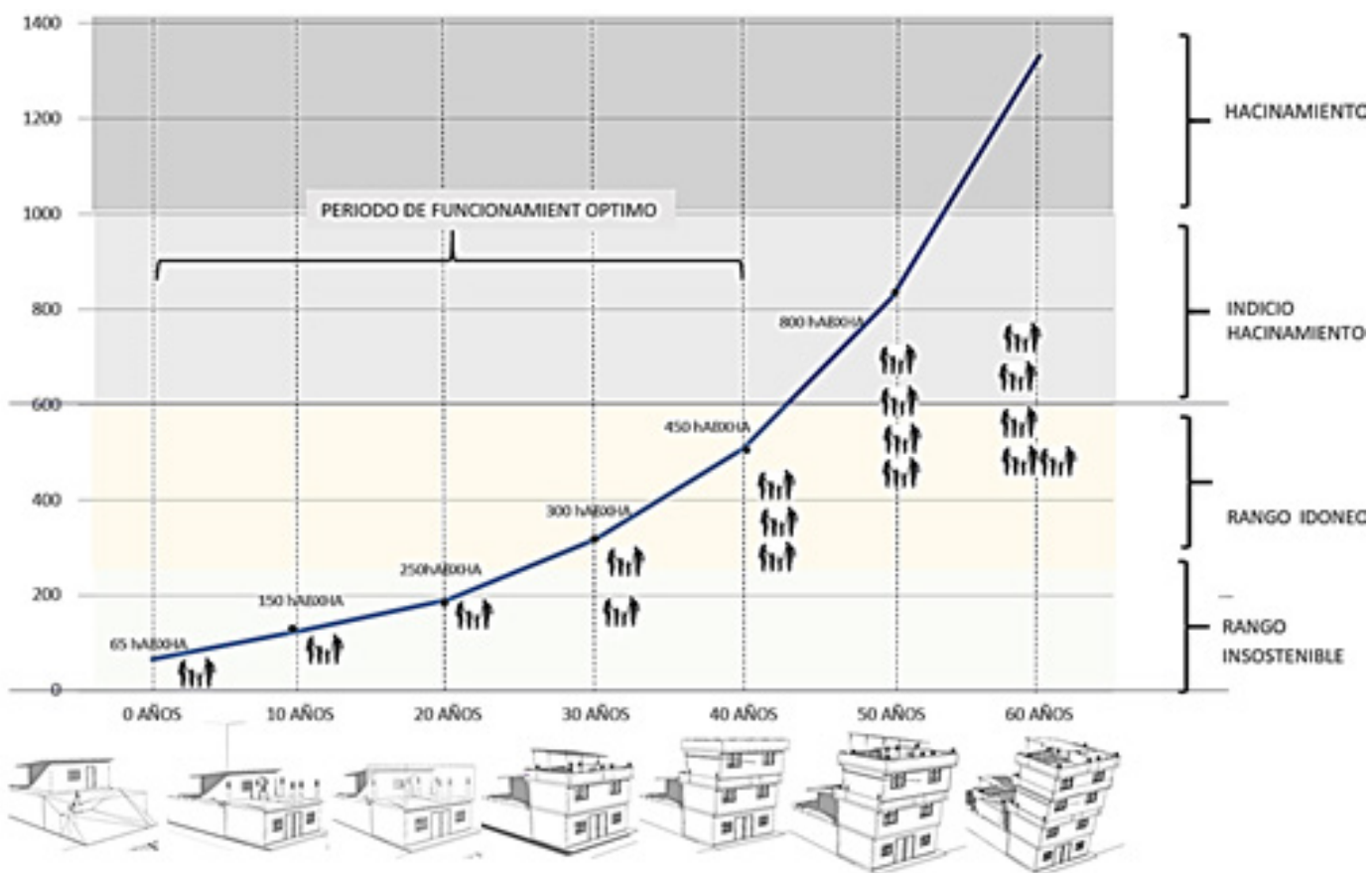

Figura 6: Densidad y Crecimiento en el tiempo en las viviendas de Atucucho Fuente: Del autor a partir de datos analizados en sitio (2017) 
la creación de una infraestructura vial importante que permite el acceso con las zonas centrales de la ciudad, dando a estos barrios una ubicación privilegiada al estar conectados con todos los sistemas centrales y líneas de transporte público, mercados y zonas de trabajo.

La densidad del barrio Atucucho en el Censo del 2010 es $137 \mathrm{hab} / \mathrm{Ha}$, media muy superior a la de Quito, que es 50 hab/Ha. Además, según los datos con los que se legaliza el barrio, la población actual de Atucucho es de 17.000 hab. y su densidad sería de $300 \mathrm{hab} / \mathrm{Ha}$, que, comparado con zonas de promoción inmobiliaria cercanas como el sector del Condado, que tiene $49 \mathrm{hab} / \mathrm{Ha}$, nos muestra que la densidad lograda por el asentamiento informal es alta en relación con la zona aledaña (Datos abiertos Distrito Metropolitano de Quito) (Figura 6).

\section{Comparación reflexiva de los dos casos}

En ambos proyectos la ubicación y conectividad juega un rol fundamental en el desarrollo del barrio y en su proceso de consolidación, como se sintetiza en las Figuras 5 y 6 . No obstante, el alto costo de la buena ubicación -Figuras 7 y 8- de los barrios informales se compensa en el tiempo. Así, el incremento de la densidad del barrio mediante el sistema de lote es hoy de $300 \mathrm{hab} / \mathrm{Ha}$, solo con un desarrollo del $65 \%$ del barrio y dos pisos de altura. Esto indica que podría seguir creciendo sin llegar a índices de hacinamiento hasta tres o cuatro pisos de altura, garantizando, al igual que ELEMENTAL, una compensación del gasto de suelo, pero de esta manera se obtendría un crecimiento sostenido en el tiempo por periodos más largos de 30 a 40 años. Notamos, sin embargo, en los dos proyectos, que la estigmatización con la que inicia todo proyecto de vivienda social confiere una plusvalía mucho menor al sector, aunque se ubique en zonas céntricas (Boano y Vergara, 2016). Esto sucede tanto en el emplazamiento de ELEMENTAL como en Atucucho. Pese a la estratégica ubicación de ambos las condiciones de rentabilidad en ninguno de los casos se equiparan con los costes de mercado en proyectos contiguos ejecutados con otro fin.

\begin{tabular}{|l|l|l|}
\hline ACCESIBILIDAD & ELEMENTAL & ATUCUCHO \\
\hline $\begin{array}{l}\text { Distancia al } \\
\text { centro }\end{array}$ & $2.68 \mathrm{~km}$ & $7.96 \mathrm{~km}$ \\
\hline Accesibilidad & $\begin{array}{l}2 \text { Líneas de } \\
\text { buses Principal } \\
\text { Av. } \\
\text { Soldado Pedro } \\
\text { Pablo }\end{array}$ & $\begin{array}{l}\text { 4líneas de } \\
\text { buses } \\
\text { Av. Mariscal Su- } \\
\text { cre. }\end{array}$ \\
\hline $\begin{array}{l}\text { Conexión con } \\
\text { transporte } \\
\text { publico }\end{array}$ & $\mathrm{Si}$ & $\mathrm{SI}$ \\
\hline
\end{tabular}

Tabla 1: Análisis comparativo de localización. Quinta Monroy versus Atucucho

Fuente: Del autor a partir de análisis de los dos casos (2017)

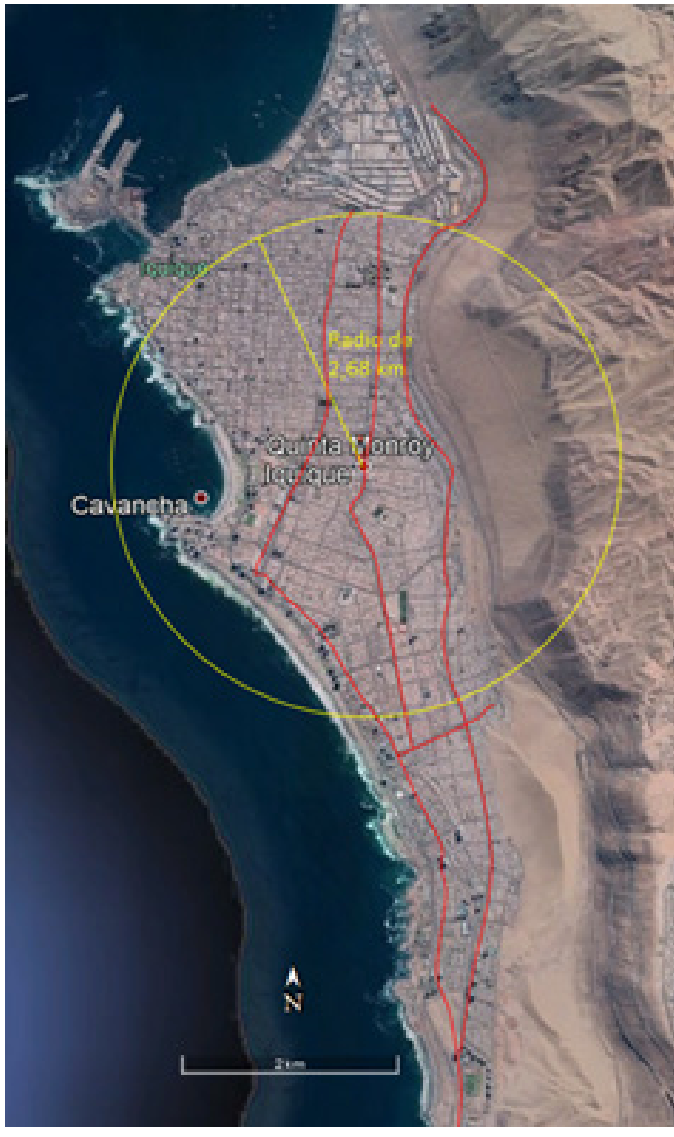

Figura 7: Mapa de localización y vías principales que conectan la Quinta Monroy - Iquique, Chile

Fuente: Del autor a partir de Google Earth (2020)

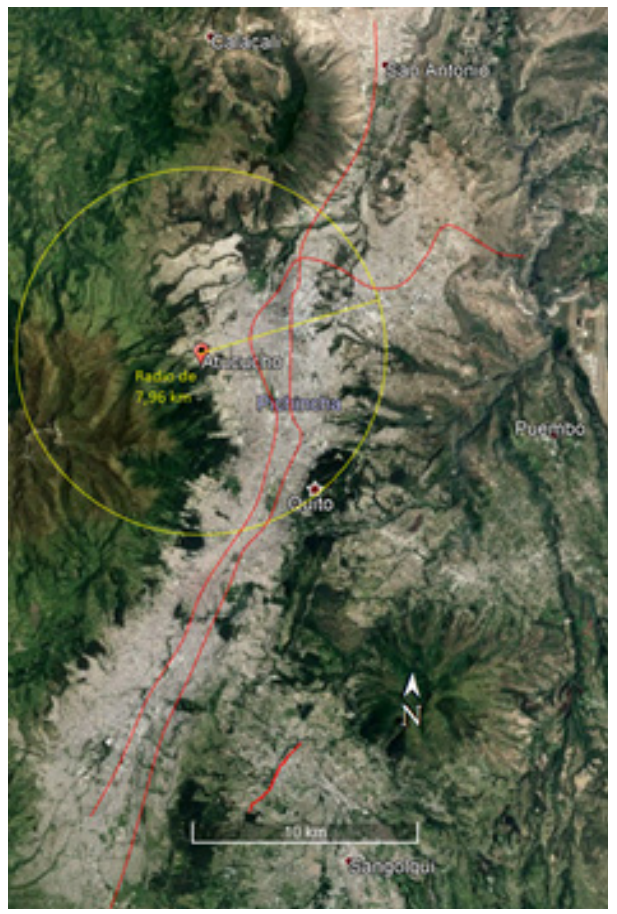

Figura 8: Mapa de localización y vías principales que conectan el barrio Atucucho - Quito, Ecuador

Fuente: Del autor a partir de Google Earth (2020) 


\subsection{Crecimiento Armónico}

Noción ideal de crecimiento planteado en ELEMENTAL

Ante los bajos presupuestos que manejan los Estados Latinoamericanos para la vivienda social, amparados en las políticas neoliberales fomentadas por el FMI desde los 70s (Davis, 2014), varios autores (González, 1998; Roch, García y Sáez, 2010) proponen que el aporte estatal debería ser la semilla del desarrollo de una futura vivienda. Además, Aravena y Lacobelli (2012), dicen que se debería también diseñar de partida el crecimiento futuro, permitiendo que "la vivienda sea una inversión y no un gasto social". Así, la casa inicial de $35 \mathrm{~m} 2$ llegaría hasta $70 \mathrm{~m} 2$, alcanzando el estándar de clase media.

De esta manera el crecimiento planteado por ELEMENTAL tiene únicamente dos variantes: la vivienda de planta baja puede crecer en forma horizontal hacia los costados adjuntos y los dúplex pueden crecer de forma lateral hacia los poros de la barra construida (Aravenay Lacobelli, 2012).

\section{Crecimiento real experimentado en Quinta Monroy}

De acuerdo con Millones (2017), a más de 15 años de proyecto se han presentado tres variables respecto al crecimiento:

1. Familias que no pudieron incrementar los $35 \mathrm{~m} 2$ por carencias económicas, pero al aumentar el componente familiar suman a la pobreza el hacinamiento. Por ello se observa en la Figura 9 que toman el área donde sería la ampliación y la cubren con elementos precarios. 2. Familias cuyos requerimientos espaciales fueron mayores de los $35 \mathrm{~m} 2$ y que se han extendido, tanto en vertical como hacia los patios y el frente, no previstos para completar estas áreas, como vemos en la Figura 10

3. Familias con nuevos núcleos familiares que incorporan áreas y nuevas viviendas, pero como esta opción no fue planteada inicialmente, para conseguir la autonomía funcional se modifica el diseño interior y se sobrecarga la estructura al incorporar un cuarto piso o extenderse hacia el frente, cubriendo los patios como vemos en la Figura 11.

4. Hay viviendas en donde la superficie de $35 \mathrm{~m} 2$ es suficiente para una familia y los terminados son de varias calidades, sin modificar la vivienda formalmente. Estas son modelo y aparecen en muchas de las fotografías que circulan sobre el proyecto propuesto por Aravena.

A pesar de no poseer datos estadísticos, lo que sí es notorio en la secuencia fotográfica (Figuras 9, 10 y $11)$, es que aún existe una tendencia de crecimiento y que esta empieza a realizarse hacia las áreas de patios o niveles superiores, que no estuvieron planificadas. También es notorio que las distintas intervenciones no solo producen, como se esperaba, una imagen de diversidad, sino que además enfatizan la desigualdad de las condiciones económicas (Boano y Vergara, 2016).

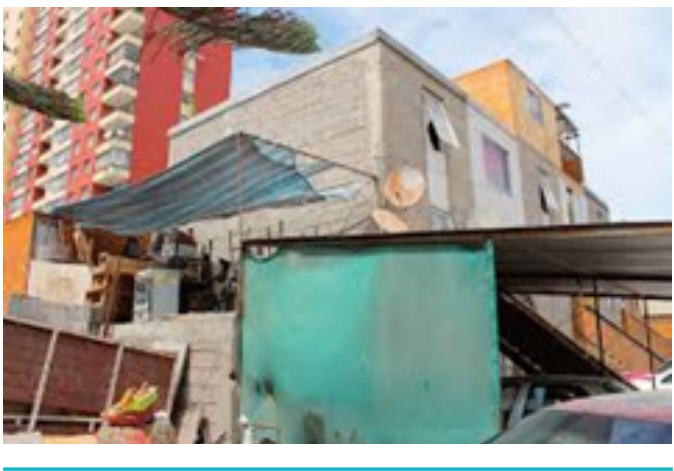

Figura 9: Adecuación de viviendas que no pueden crecer en Quinta Monroy, Iquique- Chile

Fuente: Fotografía tomada de Millones (2017)

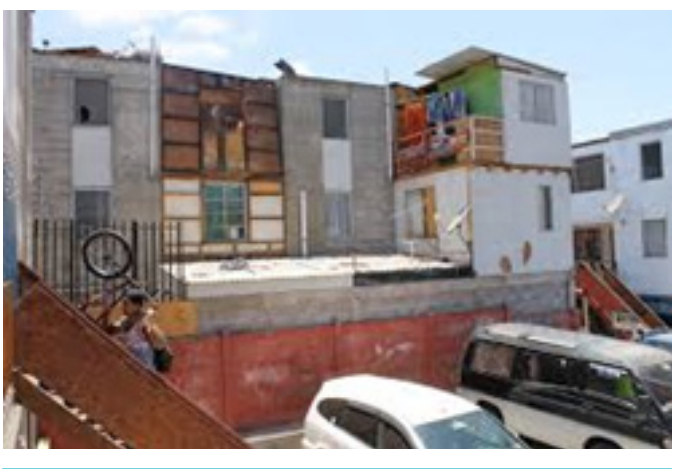

Figura 10: Viviendas que crecen hacia patios en Quinta Monroy, Iquique- Chile

Fuente: Fotografía tomada de Millones (2017)

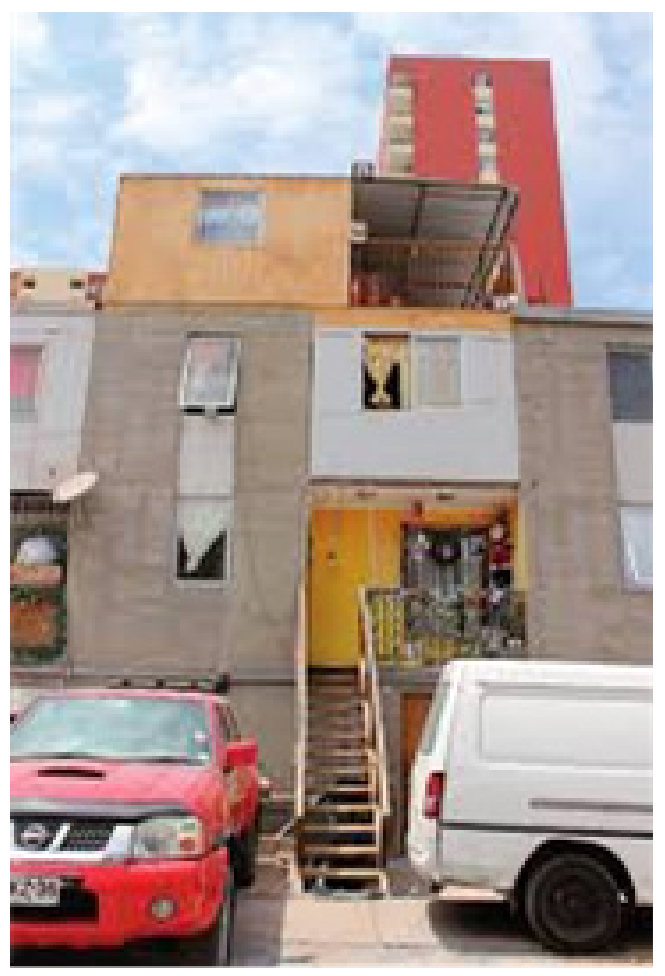

Figura 11: Vivienda que crece hacia el 4to. Nivel en Quinta Monroy, Iquique- Chile

Fuente: Fotografía tomada de Millones (2017) 


\section{Crecimiento en el barrio informal de Atucucho}

\section{a) Razones del crecimiento}

\section{Crecimiento por cambios económicos de la familia}

Si bien en los barrios de invasión, en un estado inicial todos parten de una condición económica precaria similar, a lo largo del tiempo esta varía sustancialmente. Este hecho se manifiesta en lo que denominamos grados de desarrollo de la vivienda, que son directamente proporcionales al grado de progreso familiar manifestado en su capacidad adquisitiva (Turner, 2018).

La casa no actúa como elemento aislado, sino que opera en varias escalas simultaneas, así que el desarrollo individual de la propia casa incide también en el desarrollo de su colectivo inmediato, y esta lógica se traslada al barrio, pues paulatinamente se van incrementando las mejoras en la casa y las mejoras en el propio barrio (Bolívar, 2011).

En la Figura 12 podemos ver los grados de desarrollo de la vivienda identificados en Atucucho, desde el estado inicial de una vivienda de emergencia con materiales perecederos, grado 1 , al cambio de la mediagua o vivienda transitoria con materiales temporales, grado 2 ; y en grado 3, la construcción de la casa evidencia una estructura y sus respectivas losas de hormigón, que para el grado 4 posee ya una la volumetría definida y mamposterías completas sin enlucir paredes. En cambio, en el grado 5 se puede apreciar que las predes están revestidas, estucadas y pintadas, además de elementos decorativos exteriores. Finalmente, el grado 6 se trata de viviendas que sobre la base de una casa completa edifican una nueva estructura habitable, independiente de la anterior

Con frecuencia, de la noción de casa unifamiliar se pasa a vivienda colectiva, por ello las áreas de dichas casas oscilan entre 70 a 400m2, con 7 u 8 unidades de vivienda, por lo que la vivienda se convierte en un elemento de progreso social y económico para sus habitantes (Turner, 2018).

Estos grados de desarrollo son progresivos, pero a partir del grado 5 la vivienda entra en un ciclo de estancamiento y degradación, ocasionada por la sobrecarga de la estructura, razón por la cual sería derrocada dando paso a un nuevo proceso de autoconstrucción (adaptación).

\section{Crecimiento como adaptación a los ciclos vitales}

Nos referimos a los cambios que suceden en las familias, con el transcurrir de los tiempos, relacionados a los propios ciclos de la vida (Salingaros, 2018). Las familias se juntan, incrementan en número, se fragmentan, se desarticulan, se separan e incluso mueren. Todos estos procesos naturales se manifiestan en la forma de crecimiento de la vivienda, (Turner, 2018). Por ello este crecimiento no siempre va de la mano del desarrollo económico.

Crecimiento por otras necesidades, adecuación a la forma de vivir

Los espacios al interior de la vivienda también cambian acorde a las costumbres y prácticas familiares. Así, hay salas adaptadas para el desarrollo de tiendas o garajes,
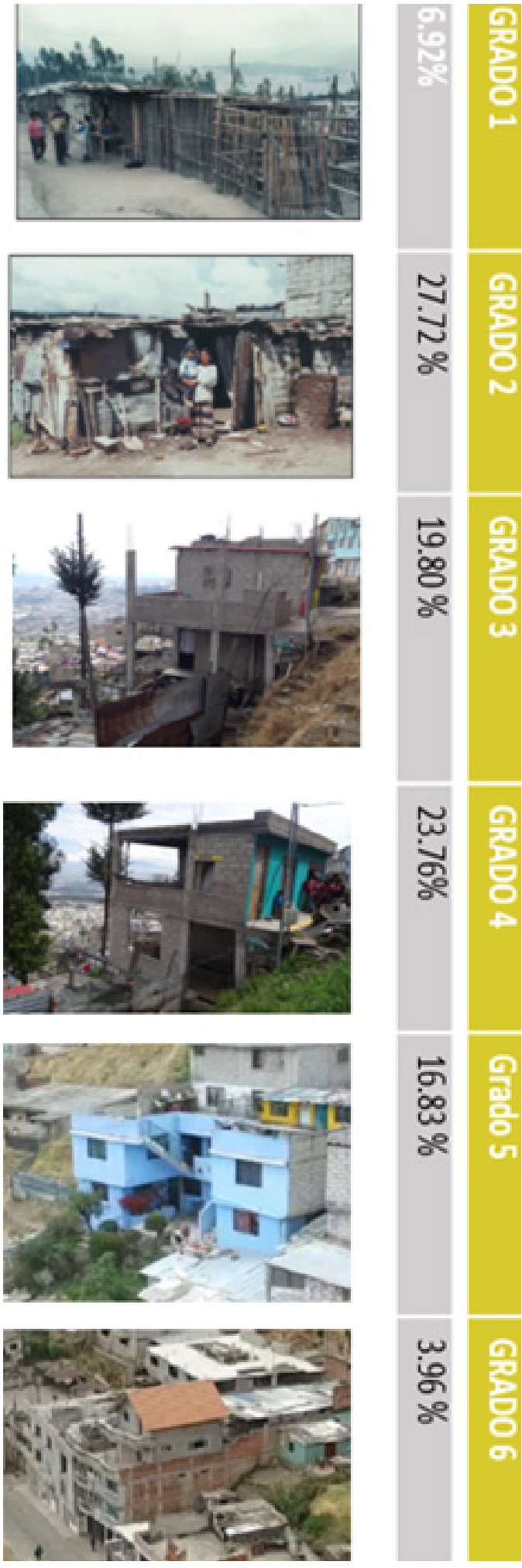

Figura 12: Grados de desarrollo en la vivienda Atucucho Fuente: Del autor a partir del análisis de caso (2019) 
o patios que se usan para talleres de trabajo. Con el paso del tiempo, cuando la persona se jubila o cuando los hijos se casan, la casa se modifica, subdividiéndose en departamentos de arriendo. Como dice Hertzberger (2015), los espacios de la casa deberían ser neutros, susceptibles de varias actividades. Esta condición es posible gracias a que en las zonas informales se construye sin normativas que regulen los usos.

\section{b) Lógica de crecimiento}

Hemos identificado, de esta manera, que existen dos tipos de variables en torno al crecimiento.
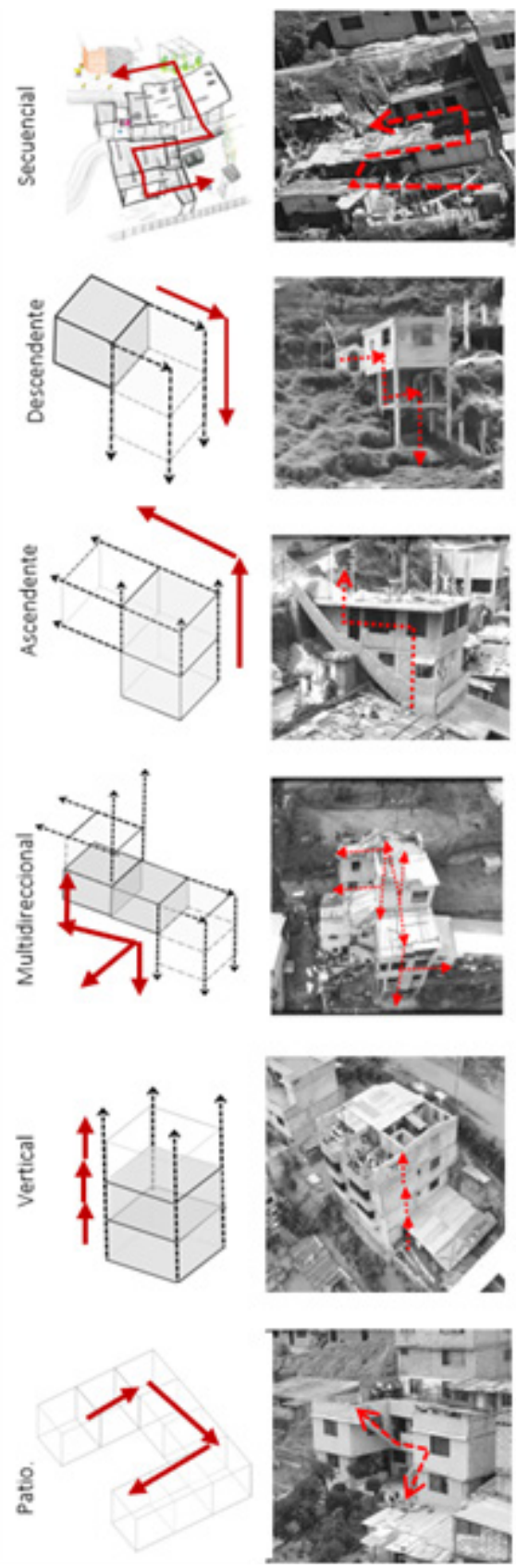

Figura 13: Grados de desarrollo en la vivienda de Atucucho.

Fuente: Del autor a partir de análisis de caso (2019)

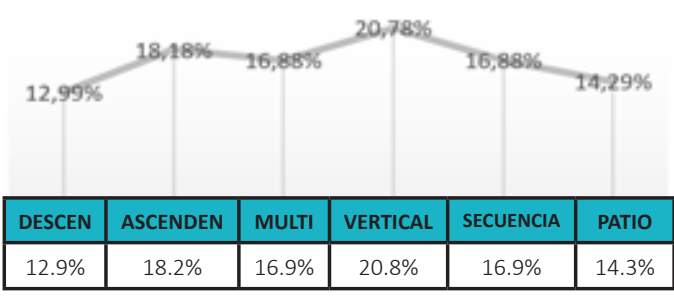

Tabla 2: Formas de crecimiento registradas en Atucucho Fuente: Del autor a partir de análisis de caso (2019)

\section{Crecimiento en casas transitorias - Crecimiento} Secuencial

Se refiere a casas que son hechas con materiales efímeros, denominadas por sus dueños como mediaguas (Klaufus, 2009), pero que, pese a las malas condiciones económicas, crecen. Estas soluciones se dan en una planta sobre la superficie del lote y se distribuyen en secuencias lineales para optimizar la distribución espacial a través del recorrido (Granja y Cuenca, 2017). De acuerdo con la Tabla 2, un 16,97\% de viviendas tienen este mecanismo de crecimiento.

\section{Crecimiento en casas definitivas - Adaptación a la pendiente}

Este tipo de crecimiento se da cuando el cambio del progreso económico de la familia va en relación directa al crecimiento de la vivienda; entonces las casas logran ser permanentes, con soportes estables (Figura 13). Este crecimiento depende de la ubicación del módulo inicial de la vivienda, en relación con la topografía:

- $\quad$ Si este se coloca en la parte inferior, la vivienda crece de manera ascendente.

- Si, en cambio, se coloca en la parte superior, crece de manera descendente.

- Si este, por ejemplo, se coloca en la parte central, el crecimiento es multidireccional.

- Además existen casas que ocasionalmente parten ya de planos definidos, y que poseen plantas tipo. Cuando el terreno es relativamente plano, en estos casos el crecimiento es de forma Vertical.

- $\quad$ Y, finalmente, si las necesidades particulares de cada familia generan un espacio de relación común, como un patio, la casa crece en torno a este, que es usado para lavanderías, huertos o incluso talleres de trabajo (Granja y Cuenca, 2017).

Como vemos, este sistema es también un mecanismo de adaptación a la pendiente, que es un factor muy importante, al menos en ciudades como Quito, con una topografía de montaña que incide en todo su contexto, y principalmente en los barrios informales que tienden a implantarse en laderas (Figura 13). 


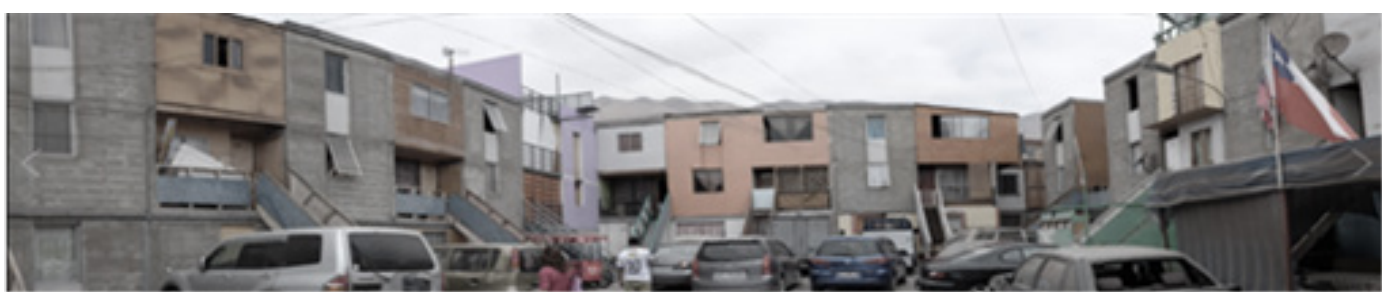

Figura 14: Espacio colectivo vecinal de Quinta Monroy, Iquique - Chile Fuente: Tomado de Millones (2017)
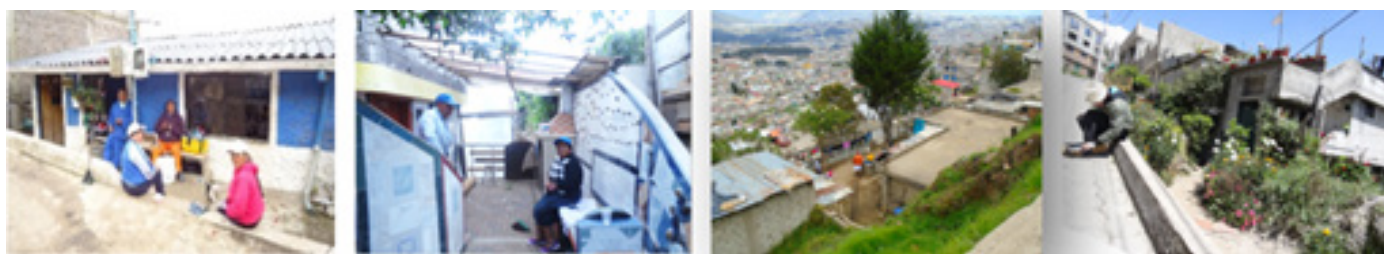

Figura 15: Espacio colectivo: zaguanes, terrazas, patios, jardines, veredas, calles, etc., en Atucucho, Quito - Ecuador Fuente: Del autor a partir del repositorio personal. Fotos del barrio Atucucho (2019)

\subsection{Elementos colectivos}

\section{Condiciones ideales del patio comunal y espacios colectivos}

Según Aravena y Lacobelli (2012), es importante vincular áreasverdesyespaciopúblicoaldiseñodelavivienda.Parten del principio de agrupación familiar, que es muy común en los asentamientos informales en torno al desarrollo de la vivienda. Por esto proponen como parámetro de agrupación la creación de un espacio colectivo de relación que simularía estas relaciones familiares en una unidad vecinal. La escala de esta se determina en 20 familias por patio, y que tenga forma cuadrada para que, además del parqueo de vehículo, reste un área central que pueda servir para la recreación, principalmente infantil (Aravena y Lacobelli, 2012) (Figura 14).

La pérdida del patio como elemento de la casa en los departamentos dúplex se compensa al incorporar una lavadora en el baño, pero no hay solución para el secado (Aravena y Lacobelli, 2012).

La distribución de las casas en torno al patio limita la conexión directa con la calle. A través del patio comunal se consigue supuestamente una mayor relación vecinal y seguridad. De esta manera, según Aravena y Lacobelli (2012), en un momento inicial las familias valoraron en 52\% como satisfactorio el patio comunal.

\section{Condiciones reales de la Quinta Monroy 15 años después}

La Quinta Monroy se construyó sobre la base de un asentamiento informal de 30 años, por lo que las veinte familias que ocuparían cada patio se basaron en las redes familiares y vecinales existentes (Aravena y Lacobelli, 2012). En este sentido, este hecho es positivo porque, en efecto, estas microrredes al interior del barrio son el motor de crecimiento de las zonas informales.
Según lo que se puede apreciar en las fotos del proyecto (Figura 14), y como sugiere Barros (2015), el patio comunal dista mucho de las imágenes iniciales difundidas por el proyecto. No ha logrado constituirse como un espacio recreativo, convirtiéndose exclusivamente en parqueadero. Como menciona Millones (2017), con respecto a la relación vecinal, en base a los testimonios que ha recopilado, la percepción general de la gente es que al inicio se dio importancia a la relación vecinal, pero esto se ha descuidado hasta desaparecer

También la falta de conexión directa con la calle evita la implementación de elementos productivos, presentes solo en las edificaciones de borde.

Se observa escasamente la incorporación de jardines. Lo que sí se percibe es que empiezan a aparecer ampliaciones con construcciones precarias hacia el patio colectivo que deterioran la imagen del conjunto (Figura 9, 10 y 11).

Tampoco existen buenas condiciones de privacidad ni de intimidad en la escala de 20 unidades de vivienda propuesta, porque además esta no se dio en todos los casos, como se planteaba desde las relaciones familiares. Por ello el patio comunal no sirve como un vínculo de conexión entre sus propietarios.

\section{Condiciones del espacio público en el barrio Informa Atucucho}

En el sistema de crecimiento que explicamos, los espacios de la vivienda se van adicionando adaptados a la topografía. Esto provoca, como podemos ver en la Figura 15, que esta interacción espacial genere una serie de espacios semipúblicos de relación, como zaguanes, pórticos, jardines, terrazas, balcones, etc., lo que se corrobora en la Tabla 3.

Las escalas de relación de los espacios se definen por proximidad y allegamiento. El grado de intimidad está entonces definido por el propio colectivo. Si bien 
hemos encontrado unidades colectivas de viviendas que aglutinan de 4 hasta incluso 20 viviendas en relación, el particular es que esta graduación se la realiza espontáneamente, lo que garantiza la convivencia.

Otro aspecto importante es la construcción de los elementos colectivos, como la calle, o incluso la infraestructura, como el alcantarillado. Se hace de manera conjunta, en mingas permanentes, lo que afianza las relaciones de proximidad, generando vecindades vinculadas por los accesos a cada vivienda. A los espacios como patios, escalinatas y terrazas se les otorga un mayor grado de intimidad, y son por lo general de uso privado al interior de núcleos familiares.

El uso del sistema de pórticos de hormigón permite, además, el desarrollo en cubierta de losas planas que generan terrazas usadas para lavado y secado de ropa, así como crianza de animales, o incluso talleres, viveros y garajes, entre otros.

En la Tabla 4 se detalla la variedad de espacios colectivos que poseen en su interior cada una las viviendas estudiadas y su escala de relación.

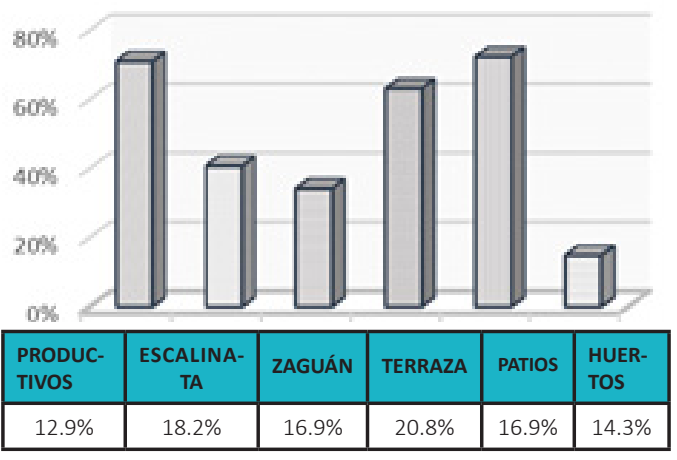

Tabla 3: Espacios colectivos en las viviendas del barrio Informal Atucucho

Fuente: Del autor a partir de análisis de caso (2019)

\begin{tabular}{|c|c|c|c|c|}
\hline & \multicolumn{2}{|c|}{ QUINTA MONROY } & \multicolumn{2}{c|}{ BARRIO ATUCUCHO } \\
\hline ESPACIO & ESCALA & USOS & ESCALA & USOS \\
\hline Patio & $\begin{array}{c}\text { 20 Fami- } \\
\text { lias Veci- } \\
\text { nal }\end{array}$ & $\begin{array}{c}\text { Parqueo } \\
\text { Y Otras }\end{array}$ & Familiar & $\begin{array}{c}\text { Lavande- } \\
\text { ría, Seca- } \\
\text { dero, Área } \\
\text { ju e g o s, } \\
\text { Jardines }\end{array}$ \\
\hline Terrazas & No & No & Familiar & $\begin{array}{c}\text { Bodegas, } \\
\text { BBQ, } \\
\text { Lavande- } \\
\text { rías, } \\
\text { Garajes }\end{array}$ \\
\hline Calle & Ciudad & Circula- \\
Ción & Vehicular & Vecinal & $\begin{array}{c}\text { peatona- } \\
\text { les, usos } \\
\text { recreati- } \\
\text { vos, vehi- } \\
\text { culares, } \\
\text { mixtas }\end{array}$ \\
\hline
\end{tabular}

Tabla 4: Variedad de espacios colectivos Quinta Monroy versus Atucucho

Fuente: Del autor a partir de análisis de caso (2019)

\subsection{Construir estratégicamente la primera mitad}

\section{Parámetros ideales de ELEMENTAL}

Desde la premisa central del proyecto, los $35 \mathrm{~m} 2$ que serían los que puede asumir la inversión estatal, deberían decidirse entre los parámetros de construir más complejos. Aravena y Lacobelli (2012) plantean lo siguiente:

a. La estructura que se calcula a través de muros y es diseñadaparasoportarelcrecimientolateralde $35 \mathrm{~m} 2$.

b. En los $35 \mathrm{~m} 2$ base se entregan baños, cocinas e instalaciones empotradas a los edificios. Se plantea que las instalaciones deberían ser siempre subterráneas.

c. El diseño de las escaleras, tanto para acceder al dúplex como al interior, se entrega en la parte inicia de la casa. Estas tienen un solo modelo y diseño.

d. Las aberturas e iluminación de la vivienda se ubican únicamente hacia el frente y costado posterior dado por la disposición en una barra lineal de la propuesta.

e. La imagen urbana del conjunto se define mediante la restricción del crecimiento de forma unidireccional hacialosporosabiertos deledifico barra, garantizando la uniformidad de altura y perfil de fachada.

\section{Parámetros reales en Quinta Monroy}

a. aComo se observa en las Figuras 9, 10 y 11 varias de las casas se han ido ampliando fuera del límite de la estructura de barra, ya sea hacia los patios o incluso hacia arriba

b. Como vemos en la Figura 16, las instalaciones eléctricas siguen siendo aéreas y se notan las conexiones complementarias, como televisión por cable, hechas en las viviendas de forma posterior

c. El esquema de escaleras se mantiene. Sin embargo, notamos que el sistema está pensado dominantemente para terrenos planos. Así, por ejemplo, en ELEMENTAL Valparaíso (Aravena \& Lacobelli, 2012) notamos cómo no todas las viviendas logran vista directa, pues el primer bloque tapa al siguiente.

d. Las aberturas de la vivienda diseñadas son adecuadas para el crecimiento de $35 \mathrm{~m} 2$, pero como es notorio en la Figura 10, los crecimientos en muchos de los casos exceden este parámetro, y estos empiezan a eliminar los patios traseros, que son una fuente de luz y ventilación primordial.

e. La imagen urbana del conjunto luce distinto a las imágenes idílicas que circulan del proyecto. Se puede notar que el nivel de incidencia de las construcciones, que sería solo el complemento, empieza a dominar y modificar el edificio lineal, tanto hacia patios como la fachada hacia las calles y patio comunal (Figura 11)

\section{Estructura e infraestructuras informales}

a. El sistema estructural desarrollado está adecuado de un 60 a $40 \%$ al sistema de hormigón armado con la creación de mallas cubicas, que se van adicionando espacialmente a través de mantener las varillas de vigas y columnas pasadas. Este 


\begin{tabular}{|c|c|c|}
\hline PARÁMETROS & QUINTA MONROY & BARRIO ATUCUCHO \\
\hline ESTRUCTURA & $\begin{array}{l}\text { La estructura de } \\
\text { muros permite } \\
\text { el crecimiento } \\
\text { solo en dirección } \\
\text { perpendicular al } \\
\text { muro }\end{array}$ & $\begin{array}{l}\text { La estructura infor- } \\
\text { mal de columnas } \\
\text { sobrepasadas y vi- } \\
\text { gas extensibles es } \\
\text { abierta }\end{array}$ \\
\hline $\begin{array}{l}\text { INFRAESTRUC- } \\
\text { TURA }\end{array}$ & $\begin{array}{l}\text { Se calcula para la } \\
\text { densidad máxi- } \\
\text { ma. } \\
\text { Se plantea una } \\
\text { sola solución de } \\
\text { partida }\end{array}$ & $\begin{array}{l}\text { Se diseña paulatina- } \\
\text { mente. Se realiza, } \\
\text { en muchos casos, } \\
\text { con materiales resi- } \\
\text { duales }\end{array}$ \\
\hline ESCALERAS & $\begin{array}{l}\text { Un solo sistema } \\
\text { de acceso a las } \\
\text { viviendas }\end{array}$ & $\begin{array}{l}\text { La escalera se utiliza } \\
\text { como mecanismo } \\
\text { de adaptación a la } \\
\text { pendiente }\end{array}$ \\
\hline $\begin{array}{l}\text { ABERTURAS } \\
\text { ILUMINACIÓN }\end{array}$ & $\begin{array}{l}\text { La barra no fun- } \\
\text { ciona en pen- } \\
\text { diente, y los cre- } \\
\text { cimientos restan } \\
\text { iluminación }\end{array}$ & $\begin{array}{l}\text { Los volúmenes se } \\
\text { alternan, mejor ilu- } \\
\text { minación }\end{array}$ \\
\hline $\begin{array}{l}\text { IMAGEN } \\
\text { URBANA }\end{array}$ & $\begin{array}{l}\text { Diversa presen- } \\
\text { cia de cables } \\
\text { eléctricos aéreos }\end{array}$ & $\begin{array}{l}\text { Muy diversa presen- } \\
\text { cia de cables eléctri- } \\
\text { cos aéreos }\end{array}$ \\
\hline
\end{tabular}

Tabla 5: Cuadro comparativo. Construir estratégicamente la primera mitad. Quinta Monroy vs. Atucucho

Fuente: Autor (2019)

sistema permite un crecimiento en el espacio multidireccional. En relación con ello el sistema de los barrios informales da mayores posibilidades de combinación e interacción en pendiente.

b. Las infraestructuras se realizan a mano, improvisando soluciones. Algunas de ellas son un collage de piezas, incluso en mal estado; otras han logrado soluciones funcionales. Sin embargo, la no planificación del sistema de redes es uno de los mayores conflictos en la solución de la vivienda, como se enfatiza en la Tabla 5. c. En vista de que la escalera está directamente vinculada al recorrido, esta se convierte en un sistema interrelacional que define la organización funcional de la vivienda, además que delinea el sistema de crecimiento, por lo que la solución responde directamente a la topografía del terreno, convirtiéndose en un mecanismo arquitectónico de adaptación a la pendiente. Aunque las soluciones intuitivas de conformación de la circulación de las viviendas tienen una estructura lógica, la respuesta técnica de las mismas no es idónea: los escalones tienen alturas y dimensiones diversas, los sistemas no son adecuadamente calculados y resueltos.

d. Como manifiesta Bolívar (1993), uno de los conflictos en los barrios informales es la tendencia a ocupar todo el terreno disponible en el lote, y al crecer en altura la vivienda queda mal iluminada y ventilada. Sin embargo, hemos notado que este problema se mitiga en zonas con pendiente en que la vivienda, por facilidad y costos, se adapta a la topografía, generando sistemas aterrazados. Como podemos ver en la Tabla 6, notamos cómo solo la forma de crecimiento vertical que corresponde al $21 \%$ de las viviendas tiende a tener un porcentaje de aberturas menor al 30\%; por lo que podríamos afirmar que en pendientes el sistema de acomodación informal, por interacción con el vecino, da mejores resultados que en terrenos planos en este aspecto.

e. En la ejecución técnica constructiva hemos encontrado afectaciones importantes para la seguridad estructural. Se identificó en las entrevistas el desconocimiento sobre las dosificaciones para el hormigón y cuantías de acero estructural. También es importante la consolidación de muros de contención que no han sido pensados.

f. Respecto a la imagen urbana del sector, si se considera de forma aislada la factura compleja y sin terminar de las viviendas en Atucucho, no es estéticamente ideal, pero en su conjunto se logra una fisonomía similar, una imagen diversa pero homogénea, tanto por los acabados como por la similitud de materiales e iconografía común que se maneja en el entorno, como vemos en la Figura 17.

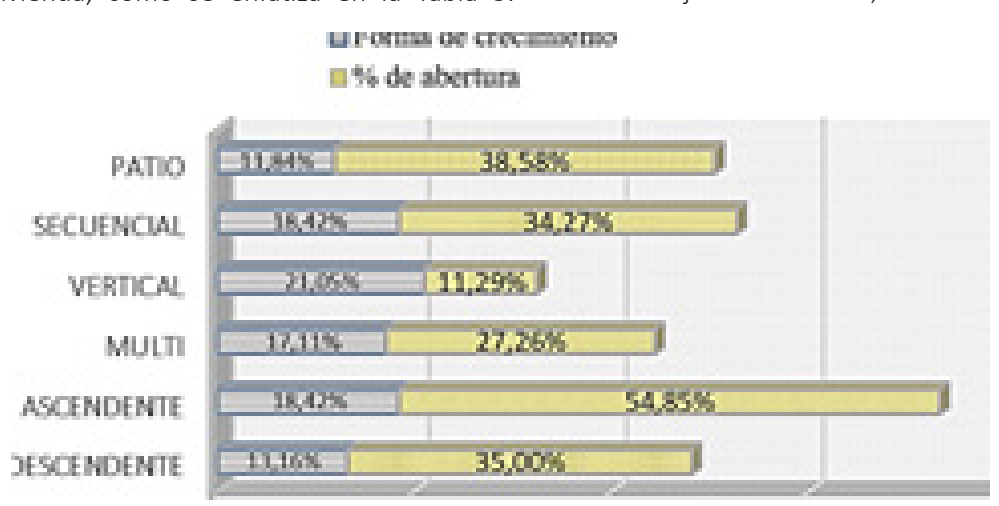

\begin{tabular}{|l|c|c|c|c|c|c|}
\hline & DESCENDENTE & ASCENDENTE & MULTIDIRECC & VERTICAL & SECUENCIAL & PATIO \\
\hline Crecimiento & $13.1 \%$ & $18.4 \%$ & $17.11 \%$ & $21.1 \%$ & $18.4 \%$ & $11.9 \%$ \\
\hline$\%$ de abertura & $35 \%$ & $54.85 \%$ & $27.26 \%$ & $11.29 \%$ & $34.27 \%$ & $28.6 \%$ \\
\hline
\end{tabular}




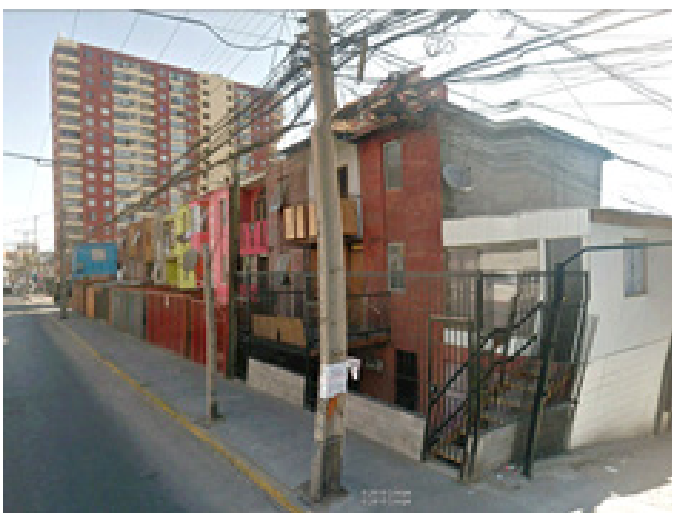

Figura 16: Imagen Urbana Quinta Monroy, Iquique - Chile (2017)

Fuente: Servicio en línea, Google Street View, (2017)

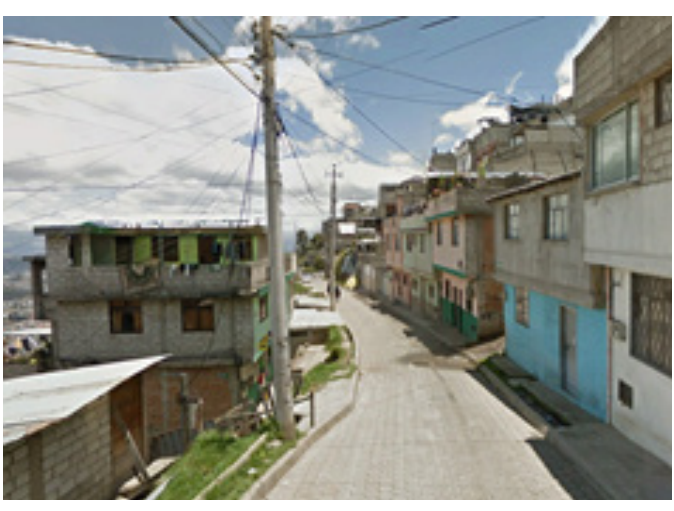

Figura 17: Imagen urbana barrio Atucucho (2017 Fuente: Autor (2017)

\subsection{ADN de clase media}

\section{Condiciones ideales de una vivienda de clase media}

Aravena y Lacobelli (2012) plantean que a través del crecimiento la vivienda inicial de $35 \mathrm{~m} 2$ podría alcanzar un estándar de clase media bajo los siguientes parámetros:

a. Área útil de la vivienda inicial de $35 \mathrm{~m} 2$, pero con la posibilidad de conseguir una vivienda de $70 \mathrm{~m} 2$ en la que se plantea un diseño interior eficiente que permita desarrollar los espacios comunes de una casa: sala, comedor, 4 dormitorios, un medio baño y un baño con capacidad para tina una cocina que puede ser independiente $y$ autónoma, que exista espacio para incorporar un parqueadero e lluminación directa en cada uno de los ambientes descritos. Para ello, aunque se elimina el patio individual en los dúplex, se propone reemplazar este rol con el uso de una lavadora.

b. Tipo de espacios- usos: Los usos determinados se restringen a lo residencial, y es así como se los piensa. Eventualmentese espera quelas viviendasquetienen relación con la calle puedan generar comercios.

c. Condiciones de habitabilidad: Las viviendas se entregan sin estucar, ni pintar, y los pisos sin revestimientos con el criterio de que estos complementos se realizarán por los propios usuarios.

d. Componentes: La cocina se entrega con las instalaciones empotradas y un fregadero. Los baños se entregan con terminados cerámicos básicos y sin inodoros. No se incorporan terrazas ni lavanderías, el espacio colectivo servirá para incorporar un parqueadero. Se entrega con escaleras interiores en madera y escaleras exteriores de hormigón.

\section{Condiciones de habitabilidad Quinta Monroy}

a. Algunas viviendas no han conseguido el estándar de $70 \mathrm{~m} 2$, otras han incorporado áreas mayores a lo previsto, cubriendo patios o extendiéndose en un cuarto piso. Destacamos que el diseño $y$ distribución interior ha optimizado el rendimiento espacial, aprovechando al máximo los reducidos espacios, con un gasto mínimo en circulaciones.

b. Se percibe incorporación de otros usos, en especial en el área de patios, lo que demuestra necesidades no determinadas. Unos pocos locales comerciales se implementan en el $20 \%$ de viviendas que colindan con la calle y sobre el que sería el retiro frontal, afectando la fisonomía volumétrica de la fachada.

c. clas condiciones de habitabilidad dependen exclusivamente de la capacidad de la familia. Como vemos en muchos de los casos, aún en el tiempo no se consigue el desarrollo óptimo y en vista de que el apoyo se limita al momento inicial, esto provoca una actitud indiferente por parte de las autoridades, al deslindarse de sus responsabilidades solo con la dotación inicial (Millones, 2017).

d. Los patios comunales han sido convertidos en parqueaderos. Se ve muy poco desarrollo de jardines en las viviendas. Únicamente las viviendas que no cumplen los parámetros de crecimiento han incorporado espacios como terrazas.

e. Las escaleras se mantienen en el estado original planteado.

\section{Condiciones de habitabilidad en el barrio informal de} Atucucho

a. Más del 63,16\% de las viviendas poseen áreas mayores al estándar de $70 \mathrm{~m} 2$. Siendo el área promedio de $106 \mathrm{~m} 2$, este parámetro es mucho mayor al considerado en ELEMENTAL, y se debe a la incorporación de espacios de tipo productivo, como vemos en la Figura 15

b. La vivienda tiene usos diversos, en especial para el trabajo artesanal, además del uso de bodegas que les permiten acumular los materiales de construcción usados en la vivienda, siendo más del $70 \%$ de las viviendas estudiadas las que han incorporado espacios productivos como talleres, tiendas, restaurantes, huertos, etc. (Figura 15). Asimismo, no todos los usos establecidos al interior de la vivienda cumplen el concepto convencional de vivienda. Se ha identificado espacios para el culto religioso. En lugar de salas, se da mucha importancia a la crianza de animales pequeños. Se mantienen cocinas tradicionales y de leña. También queremos destacar que cerca del $30 \%$ de las viviendas, aprovechando el sistema de lote, desarrollan huertos y jardines al 
interior de la vivienda. El crecimiento de la vivienda en lotes permite la creación de patios, zaguanes, jardines, terrazas, preámbulos y elementos de transición que facilitan la relación del espacio interior con el espacio colectivo de la calle. Existen acuerdos entre vecinos en los que se comparte la construcción de gradas comunes o garajes, lo que optimiza los recursos y mano de obra.

c. Los acabados interiores de las viviendas son por cuenta propia (Figura 17), y se realizan paulatinamente según las posibilidades de cada familia. La diferencia con Quinta Monroy es que en los barrios informales todavía existe un $9 \%$ que aún tienen vivienda en condiciones precarias, pisos de tierra y condiciones de humedad, insalubres, y un $14 \%$ de viviendas todavía no tienen revestimientos en paredes. Encontramos que el $73 \%$ tiene baños incorporados a la vivienda y más del $50 \%$ de estos tiene un acabado aceptable. El $70 \%$ de los casos de estudio tiene cocinas con el estado inicial de Quinta Monroy y el 30\% restante ha conseguido incorporar mesones, muebles empotrados y además independizar el área de cocina.

d. Casi el $65 \%$ de las viviendas utilizan lavadora, en las que incorporan espacios especializados para lavandería. La incorporación de parqueaderos no afecta el desarrollo de los espacios comunales de tipo vecinal ya que estos se concentran primordialmente en las calles. Las viviendas con pendiente negativa ubican los parqueos en las terrazas y las viviendas con pendiente positiva en planta baja. Solo en terrenos planos los parqueaderos ocupan el área que sería destinadas como patio (Figura 15).

e. Las soluciones de escaleras son variadas y se diseñan adaptándose a la pendiente y de acuerdo con los parámetros de crecimiento.

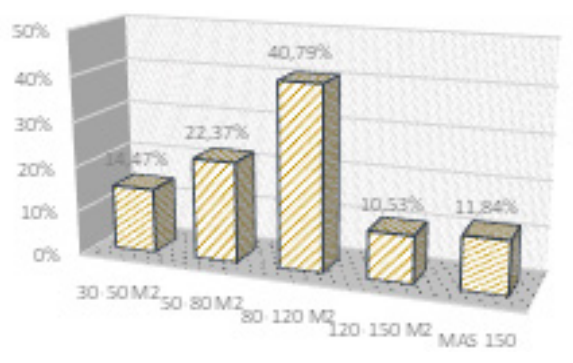

Figura 18: Áreas promedio por vivienda en el barrio Atucucho, Quito- Ecuador

Fuente: Autor

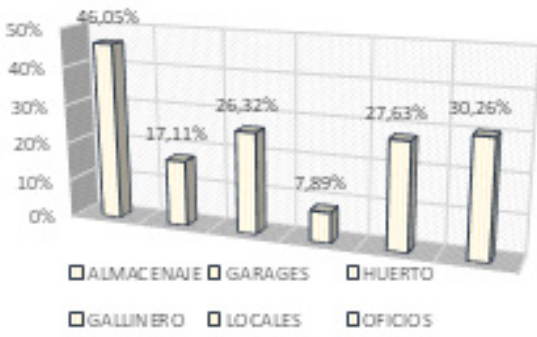

Figura 19: Usos productivos identificados en las viviendas del barrio Atucucho, Quito- Ecuador

Fuente: Autor

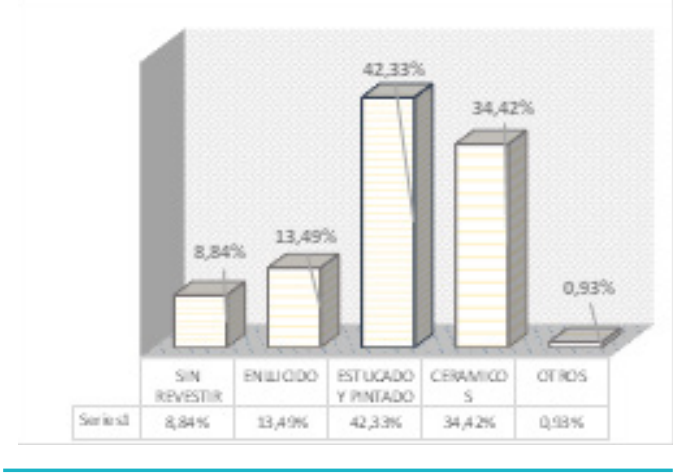

Figura 20: Acabados interiores en las viviendas del barrio Atucucho, Quito- Ecuador

Fuente: Autor

\section{Conclusiones}

El aporte de las propuestas de ELEMENTAL se centra en intentar fusionar el diseño con la autoconstrucción, y aunque este tipo de propuestas no son inéditas, si es importante desarrollar mecanismos en este sentido, con énfasis a los aspectos cualitativos. Los parámetros que ELEMENTAL establece para el diseño de vivienda progresiva son fundamentales, pero para diseñar la incrementabilidad debería tomarse en cuenta cómo los barrios informales establecen mecanismos abiertos que no se restringen a una sola variable, ni funcional ni formal, lo que permite una mayor adaptación de las condiciones específicas.

Desde esta perspectiva creemos que:

- Para garantizar una buena ubicación del proyecto que compense el costo por metro cuadrado de terrenos céntricos, se debe tener una alta densidad. Peroeste parámetrodeberíatambién serincremental en el tiempo para conferir una mayor durabilidad. Por ejemplo, iniciar en unos 300hab/Ha para llegar en un lapso de 30 años a los 600 hab/Ha esperados.

- El concepto de crecimiento armónico debe considerar además del bienestar y progreso económico de la familia, el crecimiento vegetativo y la incorporación de espacios productivos, y además considerar la ventaja de crecimiento multidireccional que se logra en el sistema de lote.

- En lo que se refiere al espacio colectivo se deben considerar las posibilidades que brinda el lote que, como sistema de relación abierto, permite una organización e interacción al interior de la manzana, provocando la creación de colectivos como patios y escalinatas que se autoconfiguran espontáneamente por proximidad y allegamiento. Más que espacios comunales, como el patio central de ELEMENTAL, se deben crear escalas de relación a través de puntos de convivencia tanto barrial como vecinal, e incluso familiar, y destinar espacios específicos para ello. Esto podría realizarse en, por ejemplo, plazas a escala barrial, calles a escala vecinal y patios a escala familiar. Si estas escalas no se definen adecuadamente, provocan la pérdida de aprobación, identidad, relación y convivencia. 
- La intervención estatal debe poner énfasis, además de programas de vivienda, el desarrollo de espacios colectivos de calidad complementarios, plazas, plazoletas y equipamiento barrial, evitando barrios conformados solo de estructuras de vivienda.

- Se deben buscar mecanismos técnicos idóneos para el sistema de estructura de pórticos. Adoptado dominantemente por los barrios informales, consiguen un crecimiento multidireccional.

- Se deben desarrollar estrategias para que el sistema de redes e instalaciones logren ser incorporados desde el principio y conseguir que estas instalaciones sean soterradas, y de calidad y cantidad necesarias para soportar las densidades de población previstas. Este rol debería ser ineludiblemente estatal. - También, así como es necesario que la casa llegue a una estructura habitacional de al menos los $70 \mathrm{~m} 2$, se debe considerar la incorporación de 20 a $40 \mathrm{~m} 2$ para elementos productivos, ideal para países en desarrollo, pues la vivienda es además un elemento productivo.

- Creemos que el mayor problema de los barrios informales es que estos sistemas abiertos no tienen, en todos los casos, una solución técnica. La estructura no se calcula o los espacios y forma en que crecen no siempre consideran las condiciones de iluminación necesaria, y menos aún la distribución espacial óptima. Todos estos aspectos no son constructivos: son principalmente temas de diseño. Por ello debemos conseguir que el diseño arquitectónico, como noción inmaterial, llegue a manos de los que autoconstruyen.

Este podría ser el verdadero rol de la intervención estatal: el valor abstracto de las ideas arquitectónicas, que son el factor real del que adolecen los barrios informales.

Creemos, finalmente, que la premisa de que la vivienda social deba ser considerada como una inversión y no como un gasto social debería completarse con la idea de que la vivienda no solo debería ser una inversión, sino además un medio de producción de riqueza y un medio de interacción social.

\section{Referencias bibliográficas}

Adler, V. y Vera, F. (Eds.) (2018). Vivienda ¿Qué viene? De pensarlaunidad a construirlaciudad. Nueva York, USA:BID.

Aravena, A. y Lacobelli, A. (2012). Vivienda incremental (social), innovación en la planificación habitacional, diseño comunitario. Berlín, Alemania: Hatje Cantz (Bookport).

Aravena, A., Lacobelli, A. y Elemental (2012). Elemental: manual de vivienda incremental y diseño participativo = incremental housing and participatory design manual. Ostfildern, Alemania: Hatje Cantz.

Barros, F. (2015). La desigualdad es ELEMENTAL: Conjeturas ideológicas para una crítica a Quinta Monroy. NOPINION El blog de Arkrit. Recuperado de http://dpa-etsam.aq.upm.es/gi/arkrit/ blog/la-desigualdad-es-elemental-conjeturasideologicas-para-una-critica-a-quinta-monroy/
Blas, P. (2015). Las ruinas que dejó el boom de la vivienda popular en México. Revista Magis ITESO, (446), 16-25.

Boano, C., y Vergara, F. (2016). Bajo escasez ¿Media casa basta? Reflexiones sobre el Pritzker de Alejandro Aravena. Revista de Arquitectura, 21(31), 37-46. doi:10.5354/0719-5427.2016.42516

Bolívar, T. (1993). Densificación de los barrios autoproducidos en la capital de Venezuela: Riesgos y Vulnerabilidad. Caracas, Venezuela: Universidad Central.

Bolívar, T. (2011). Acercamiento a las más importantes manifestaciones en la obra de los auto productores anónimos. En F. Carrión (Ed.), Desde adentro: Viviendo la construcción de las ciudades con su gente (pp. 109-155). Quito, Ecuador: OLACHI.

Carrión, F. y Erazo, J. (2012). La forma urbana de Quito, una historia de centros y periferias. Bulletin del'Institut Français d'Études Andines, 41 (3), 503-522. doi:10.4000/bifea.361

Cuenca, M. (2019). Caracterización de la periferia urbana latinoamericana andina, caso Quito. (Tesis doctoral). Universidad Politécnica de Madrid, Madrid, España. doi:10.20868/UPM.thesis.57499.

Cueva, S., Ospina, O. y Navas, G. (2011). Investigación solicitada por UERB y AZC MDMQ. Informe informalidad, asentamientos humanos irregulares y planificación urbana del DMQ. Quito, Ecuador: Instituto de la Ciudad de Quito, Municipio del Distrito Metropolitano de Quito.

Davis, M. (2014). Planeta de ciudades miseria. Madrid, España: AKAL.

García, F., Torres, D. y Tugas, N. (2008). El tiempo construye: el Proyecto Experimental de Vivienda (PREVI) de Lima: génesis y desenlace. Barcelona, España: Gustavo Gili.

González, X. (1998). Flexible para sobrevivir. A+T. Revista trimestral de Arquitectura y Tecnología (12), 4-11.

Granja, M. y Cuenca, M. (2017). La ciudad paso a paso: Métodos de interacción para la configuración de barrios informales desde sus propias lógicas Quito- Ecuador. IX Seminario Internacional de Investigación en Urbanismo, Barcelona-Bogotá, Barcelona, España: Recuperado de https://arqdis.uniandes.edu.co/Seminario_SIIU/ memorias/BCN/MT2/102BCN_GranjaMariaBelen.pdf

Habraken, J. (1998). The structure of the ordinary. Cambridge, USA: MIT Press.

Hertzberger, H. (2015). Architecture and structuralism: the ordering of space. Rotterdam, Netherlands: Nai010 Publishers,

Huidrobo, F., Torres, D. y Tugas, N. (2010). PREVI Lima y la experiencia del tiempo. Riurb Revista Iberoamericana de Urbanismo: Vivienda Recuperada, (3), 10-19.

Klaufus, C. (2009). Construir la ciudad andina: Planificación y autoconstrucción en Riobamba y Cuenca. Quito, Ecuador: Abya-Yala. 
Massad, F. (2016). Aravena: La autoconstrucción de una infamia. La viga en el ojo. ABC Blogs. Recuperado de https://abcblogs.abc.es/viga-en-el-ojo/otros-temas/ aravena-la-autoconstruccion-de-una-infamia.htm

Millones, Y. (2017). La otra mitad de la Quinta Monroy. Revista de Arquitectura 22, (32), 6772. doi: 10.5354/0719-5427.2017.46147

Monteys, X. (2017). La calle y la casa: Urbanismo de interiores. Barcelona, España: Gustavo Gili.

Peltre-Wurtz, J. (2004). Luchar para comer Estrategias familiares para la alimentación en sectores populares. Quito, Ecuador: Ediciones Abya-yala.

Roch, F., García, J. y Sáez, E. (2010). Ciudad, vivienda y hábitat en los barrios informales de Latinoamérica. En Ciudad, territorio y paisaje: Reflexiones para un debate multidisciplinar (pp. 105-118). Madrid, España: CSIC.

Sáez, E., García, J. y Roch, F. (2010). La ciudad desde la casa: Ciudades espontaneas en Lima. Revista INVI, 25(70), 77-116. Recuperado de http:// revistainvi.uchile.cl/index.php/INVI/article/view/503

Salingaros, N. (2018). Forma, lenguaje y complejidad: Una teoría unificada de la arquitectura. Madrid, España: Asimetrías ediciones.

Salingaros, N., Brain, D., Duany, A., Mechaffy, M. y Philibert-Petit, E. (2006). Vivienda social en Latinoamérica: Una metodología para utilizar procesos de autoorganización. En Congreso Ibero-Americano de Vivienda Social en Brasil. Florianópolis, Brasil.

Schütz, E. (1996). Ciudades en américa latina: Desarrollo barrial y vivienda. Santiago, Chile: Ediciones Sur.

Turner, J. F. C. (2018). Autoconstrucción por una autonomía del habitar: Escritos sobre vivienda urbanismo autogestión y holismo. La Rioja, España: Pepitas de Calabaza.

Zevallos, O. (1996). Ocupación de laderas: Incremento del riesgo por la degradación ambiental urbana en Quito, Ecuador. En Ciudades en Riesgo: Degradación ambiental, riesgos urbanos y desastres (pp. 106117). Panamá, Panamá: Red de Estudios Sociales en Prevención de Desastres en América Latina. 